\section{Naturally occurring and technogenic radionuclides in Yerevan (Armenia) soils: Background values spatial distribution and stochastic health risk assessment}

\author{
ANTONIO ARUTA ${ }^{1}$, LILIT SAHAKYAN ${ }^{2}$, GEVORG \\ TEPANOSYAN ${ }^{2}$, NONA MOVSISYAN ${ }^{2}$, SALVATORE \\ DOMINECH $^{3}$, ANNAMARIA LIMA ${ }^{1}$, OLGA BELYAEVA ${ }^{2}$ \\ AND STEFANO ALBANESE ${ }^{1}$ \\ ${ }^{1}$ University of Naples Federico II \\ ${ }^{2}$ Center for Ecological-Noosphere Studies of NAS RA \\ ${ }^{3}$ Tongji University \\ Presenting Author: antonio.aruta@unina.it
}

The activity concentration of both naturally occurring (NOR) (i.e. U-238, Th-232, K-40) and technogenic (Cs-137) radionuclides was determined on 51 soil samples collected across Yerevan, the capital of Armenia. Measures were carried out at Center for Ecological-Noosphere Studies National Academy of Sciences, RA (CENS) with a High Purity Ge detector-based gamma spectrometry system. Data were georeferenced and the Multifractal IDW (MIDW) interpolation was used to generate grid of the distribution patterns of radionuclide activity. The Concentration-Area (C-A) analysis was applied to grids [1] to determine intervals in maps. Further, the Spectrum-Analysis (SA), based on a Fourier spectral analysis, was also applied to generate radionuclide activity background distribution patterns.

At each sampling location, the values of the main indices used to assess the health risk [2] related with low dose ionizing radiation exposure were evaluated for NOR and Cs-137, as well.

Result showed that low background values of NOR are mostly featuring the south and south-east sector of the city, in correspondence with sedimentary geological formations, whereas moderately high levels of NOR characterize soils originated from weathering of andesite-basalt lavas and ignimbrite tuffs in the central and northern territory (e.g., fig.1). The spatial distribution of Cs-137 activity follows, instead, an altitude-dependent pattern probably due to the global radioactive fallout.

With regards to risk, the highest individual values of radiological indices occur in correspondence with samples collected in the north. An excess lifetime cancer risk (ELCR) assessment based on Monte Carlo (MC) approach indicates that there is a $32 \%$ probability for a local citizen to be exposed to a risk higher than the world average value of 2.9E-04 [2] during his life. Sensitivity analysis applied to the MC simulation showed that U-238 and Th-232 strongly influence the value of ELCR, followed by K-40 and Cs- 137 .

References

[1] Zuo, R., \& Wang, J. (2020). ArcFractal: An ArcGIS AddIn for Processing Geoscience Data Using Fractal/Multifractal Models. Natural Resources Research, 29(1), 3-12.

[2] UNSCEAR. (2000). Sources and effects of ionizing radiation: Vol. I (Issue Annex B).

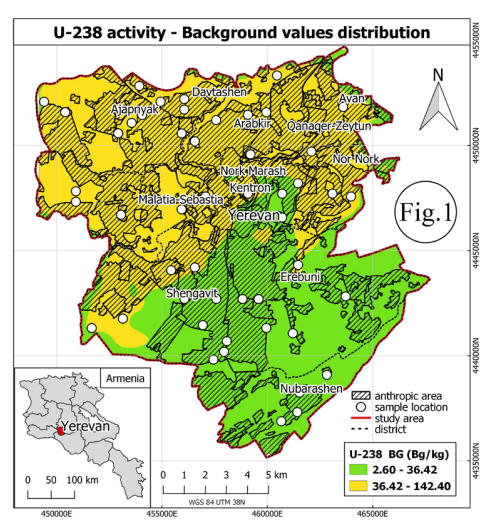

